\title{
Fine particulate matter and ischemic heart diseases in relation to sex. An ecological time series study
}

\author{
Paola Cristina Ribeiro', Luiz Fernando Costa Nascimento", Ana Aparecida Almeida"l, Marcelo dos Santos Targalv,
} Ana Cristina Gobbo Cesarv

Postgraduate Program on Environmental Sciences, Universidade de Taubaté (UNITAU), Taubaté (SP), Brazil

\begin{abstract}
'BSc. Master's Student, Postgraduate Program on Environmental Sciences, Universidade de Taubaté (UNITAU), Taubaté (SP), Brazil.

(Dorcid.org/0000-0002-1252-5731

"MD, PhD. Researcher, Postgraduate Program on Environmental Sciences, Universidade de Taubaté (UNITAU), Taubaté (SP), Brazil.

(D)orcid.org/0000-0001-9793-750X

"'PhD. Researcher, Postgraduate Program on Environmental Sciences, Universidade de Taubaté (UNITAU), Taubaté (SP), Brazil.

(D)orcid.org/0000-0002-0410-5446

ivphD. Researcher, Postgraduate Program on Environmental Sciences, Universidade de Taubaté (UNITAU), Taubaté (SP), Brazil

(Dorcid.org/0000-0002-4140-3493

vPhD. Assistant Professor, Instituto Federal de Educação Ciência e Tecnologia de São Paulo (IFSP), Campus Bragança Paulista (SP), Brazil.

(Dorcid.org/0000-0001-8618-8654
\end{abstract}

KEY WORDS:

Cardiovascular diseases.

Air pollutants.

Particulate matter.

\begin{abstract}
BACKGROUND: Exposure to some air pollutants is associated with cardiovascular diseases. The objective of this study was to quantify the effect of exposure to fine particulate matter in hospitalizations due to ischemic heart disease and the costs to the healthcare system.

DESIGN AND SETTING: Time-series ecological study conducted in Taubaté, Brazil.

METHODS: Data on hospitalizations due to ischemic heart diseases (ICD I-20 to I-24) in the municipality of Taubaté (SP), Brazil, among adults of both sexes aged 40 years and over, from August 2011 to July 2012, were obtained from DATASUS. Fine particulate matter $\left(\mathrm{PM}_{2.5}\right)$ concentrations were estimated from a mathematical model. Poisson regression was used in statistical analyses to estimate the relative risks of exposure to $\mathrm{PM}_{25}$ for both sexes and after stratification according to sex. The excess of hospitalizations and consequent excess expenditure for the healthcare system were calculated.

RESULTS: There were 1040 admissions, among which 382 had ischemic heart diseases (257 males). The mean $\mathrm{PM}_{2.5}$ concentration was $13.2 \mu \mathrm{g} / \mathrm{m}^{3}$ (SD = 5.6). Significant effects from exposure were noted 4 and 5 days after exposure (lag 4 and lag 5) for both sexes and for male sex; for female sex, the effect was 2 days after exposure (lag 2). There were 59 excess hospitalizations for an increase in $\mathrm{PM}_{25}$ concentration of $5 \mu \mathrm{g} / \mathrm{m}^{3}$ and excess expenditure of US\$150,000 for the National Health System.

CONCLUSIONS: An excess of hospital admissions due to ischemic heart disease, with excess expenditure, was identified consequent to $\mathrm{PM}_{2.5}$ exposure.
\end{abstract}

\section{INTRODUCTION}

Over the period from August 2011 to July 2012, cardiovascular diseases accounted for 1.1 million hospitalizations in Brazil, generating a cost of approximately US\$ 1 billion. In the state of São Paulo, the most populous and developed state in Brazil, there were approximately 260,000 hospitalizations, costing approximately US\$ 300 million. Specifically, the 65,000 hospitalizations due to ischemic heart diseases consumed resources of the order of US\$ 130 million. ${ }^{1}$

Cardiovascular diseases are typically associated with factors such as smoking, hypercholesterolemia, systemic arterial hypertension, family history of ischemic diseases of the heart, smoking, obesity and sedentary lifestyle. Moreover, some studies have identified an association between exposure to air pollutants and these diseases. Several positive associations have been found in relation to exposure to fine particulate matter $\left(\mathrm{PM}_{2.5}\right)$, i.e. particles with an aerodynamic diameter of less than $2.5 \mu$. In urban areas, $\mathrm{PM}_{2.5}$ constitutes about 50 to $60 \%$ of $\mathrm{PM}_{10}$ (particulate material with an aerodynamic diameter of less than $10 \mu) .^{2}$ These particles result from burning fuels such as coal, gasoline, oil and biomass; from processes involving high temperatures such as smelting and steel production; and from soil dust. The particles can reach the terminal portions of the respiratory tree. The material adsorbed onto the particle's surface depends on the region of the city from which it originated. ${ }^{3,4}$

In the region of the Paraíba valley, in the state of São Paulo, these particles present high ion concentrations of $\mathrm{SO}_{4}^{2-}, \mathrm{NH}_{4}^{+}$and $\mathrm{K}^{+}$, with long half-lives of the order of days to weeks. The particles have the capacity for dispersal over long distances, of the order of 100 to $1000 \mathrm{~km} .{ }^{3,4}$

Higher risk of death due to ischemic heart disease, arrhythmia, heart failure and cardiac arrest has also been correlated with long-term exposure to $\mathrm{PM}_{2.5}{ }^{5,6} \mathrm{On}$ the other hand, over the last decade, epidemiological studies have highlighted that the effects of pollution 
and the risk of cardiovascular diseases are more evident among women than among men, ${ }^{7-9}$ but without reaching any consensus in this regard.

The $\mathrm{PM}_{2.5}$ concentration is usually quantified by state environmental agencies, but this monitoring does not exist in all municipalities or in all states in Brazil. One alternative for estimating these concentrations is to use modeling methods such as the Coupled Chemistry Aerosol and Tracer Transport model for the Brazilian Atmospheric Modeling System (CCATT-BRAMS). This considers the emission and transportation of various aerosol gases and forms of particulate matter, with daily estimates of various pollutants. ${ }^{10}$ The Center for Weather Forecasting and Climate Studies of the Brazilian National Institute for Space Research (Centro de Previsão de Tempo e Estudos Climáticos, Instituto Nacional de Pesquisas Espaciais, CPTEC-INPE) runs this model in an operational manner, producing daily data every three hours, with a horizontal resolution of $25 \mathrm{~km}$ by $25 \mathrm{~km}, 40$ meters above ground level, covering all of South America. ${ }^{10}$ This model has been used in some Brazilian studies. ${ }^{11,12}$

\section{OBJECTIVE}

The objective of this study was to estimate the association between exposure to fine particulate matter $\left(\mathrm{PM}_{2.5}\right)$ and hospitalizations due to ischemic heart disease in the city of Taubaté, a medium-sized city in the state of São Paulo, according to the sex of the patients, using data estimated through mathematical modeling.

\section{METHODS}

A time-series ecological study was carried out in the city of Taubaté, based on estimates of $\mathrm{PM}_{2.5}$ concentrations that were obtained from the CCATT-BRAMS daily monitoring system (http://meioambiente.cptec.inpe.br/).

Taubate is located in the mesoregion of the Paraíba valley, in the state of São Paulo, between the two largest economic axes of Brazil: $130 \mathrm{~km}$ from São Paulo and $280 \mathrm{~km}$ from Rio de Janeiro. Its geographical coordinates are $23^{\circ} 01^{\prime} \mathrm{S}$ and $45^{\circ} 33^{\prime} \mathrm{W}$, and it has an approximate population of 300,000 inhabitants in a territorial area of $625 \mathrm{~km}^{2}$. It has a humid subtropical climate and lies alongside the Dutra Highway, which links São Paulo to Rio de Janeiro and is characterized by intense vehicular traffic. It has two hospitals that attend patients within the Brazilian National Health System (Sistema Único de Saúde, SUS).

The data from hospitalizations due to ischemic heart disease that were used in this study related to conditions classified under codes I-20 to I-24 of the International Classification of Diseases, $10^{\text {th }}$ revision (ICD-10). These data covered the period from August 1,2011 , to July 31, 2012, and were collected from the SUS website (DATASUS) (http://www2.datasus.gov.br/DATASUS/index.
php?area=0203\&id=6926\&VObj=http://tabnet.datasus.gov.br/cgi/ deftohtm.exe?sih/cnv/ni). The values were organized in columns, separated according to municipality code, date of hospitalization, diagnosis and age. Only adults aged 40 years and over were considered in this study, and these subjects were subsequently stratified as male and female.

The following variables were considered in analyzing the data. The dependent variable was the daily number of hospitalizations due to cardiovascular diseases, obtained from DATASUS. The independent variables were the concentration of the pollutant $\mathrm{PM}_{2.5}$ $\left(\mu \mathrm{g} / \mathrm{m}^{3}\right)$, temperature $\left({ }^{\circ} \mathrm{C}\right)$ and relative humidity $(\%)$, which were obtained from CPTEC-INPE. Days of the week and long-term seasonality were the control variables.

In studies on the impact of air pollution on health, it is necessary to take into account the short-term trend represented by the days of the week because, at weekends, the number of hospital visits is lower than on weekdays. Long-term seasonality is another important time trend, since meteorological factors and pollutant concentrations vary during the year. Regarding air temperature and relative humidity, these climatic variables are correlated with hospital admission rates and their inclusion changes the coefficients and, consequently, the relative risks in an important way. It is also important to note that practically all studies on this topic have included these variables, which has made these studies comparable with each other. ${ }^{5-9}$

The frequency distributions of the different independent variables, i.e. $\mathrm{PM}_{2.5}$ concentration, temperature and relative air humidity, and the daily numbers of cases of hospitalization were expressed as means, standard deviations and minimum and maximum values. This was done using the Statistica v.7 software.

The data were analyzed using the Poisson regression generalized additive model because the hospitalizations were numerical data that followed Poisson distribution. This regression is expressed by equation (1):

$\operatorname{Ln}(\mathrm{HA})=\beta_{0}+\beta_{1}(\mathrm{CONC})+\beta 2(\mathrm{RH})+\beta 3(\mathrm{~T})+\beta_{4}(\mathrm{SEASON})+\beta_{5}(\mathrm{D})$

where:

$\beta$ 's are regression coefficients;

HA is daily hospital admission;

CONC is the air pollutant concentration;

$\mathrm{RH}$ is the relative humidity value;

$\mathrm{T}$ is the temperature value;

SEASON is the long-term trend (seasonality); and

$\mathrm{D}$ is the day of the week.

This model provided a coefficient (coeff) that could be transformed into the relative risk (RR) of occurrence of the outcome, according to the expression $\mathrm{RR}=\exp ^{\text {(coeff) }}$. These $\mathrm{RRs}$ were calculated 
with their respective $95 \%$ confidence intervals for hospitalizations due to ischemic heart diseases for females, males and both sexes.

We also tested whether the effect estimates were statistically different between males and females by computing the $95 \%$ confidence interval using the following equation (2):

$\mathrm{Q}_{1}-\mathrm{Q}_{2} \pm 1.96 \sqrt{\left(S E_{1}^{2}\right)+\left(S E_{2}^{2}\right)}$

where:

$\mathrm{Q}_{1}$ and $\mathrm{Q}_{2}$ are coefficients of these categories; and $\mathrm{SE}_{1}$ and $\mathrm{SE}_{2}$ are the respective standard errors. ${ }^{13}$

Since the effects of exposure may occur either on the same day or on subsequent days, lags of 0 to 7 days after exposure were taken into consideration.

In these analyses, an increase in exposure to the $\mathrm{PM}_{2.5}$ pollutant of $5 \mu \mathrm{g} / \mathrm{m}^{3}$ was calculated to determine the percentage increase (PI) in RR, and this was expressed through equation (3):

$\mathrm{PI}=\left[\exp \left(\beta^{\star} \Delta \mathrm{C}\right)-1\right]^{\star} 100$

where:

$B$ is the value provided by the Poisson regression; and $\Delta \mathrm{C}$ is the variation in the fine particulate concentration, which in this case was $5 \mu \mathrm{g} / \mathrm{m}^{3}$. Considering that $\mathrm{PM}_{2.5}$ constitutes approximately $50 \%$ of $\mathrm{PM}_{10}$, this value can even be used for comparison purposes with other studies.

From this increase in $\mathrm{PM}_{2.5}$ concentration, for both sexes and separately for the male and female sexes, we estimated the proportional attributable risk (PAR), which was given by PAR $=[1-1 / R R]$. The excess of hospitalizations was also estimated through the expression $\mathrm{PAF}=\left(\mathrm{PAR}^{*} \mathrm{~N}\right)$, where $\mathrm{PAF}$ is the population attributable fraction and $\mathrm{N}$ is the number of hospitalizations for both sexes and separately for the male and female sexes. From this excess number of hospitalizations, it was possible to estimate the excess expenditure in accordance with the number of hospitalizations due to ischemic heart diseases, which was obtained from the DATASUS website.

\section{Ethical criteria}

This study was not evaluated by an internal review board (ethics committee), because the records used are available from DATASUS, which is a public website.

\section{RESULTS}

During the study period, 1040 hospitalizations relating to diseases of the cardiovascular system (ICD-10 codes I-00 to I-99) occurred, among which 903 (87.0\%) were cases of individuals aged 40 years and over. There were 382 hospitalizations due to ischemic heart disease among individuals aged 40 years and over in the city of Taubaté (SP) and 257 (67.3\%) of these cases were among men.

The pollutant values observed over this period and the hospitalizations due to ischemic heart diseases were expressed as averages, as shown in Table 1. The $\mathrm{PM}_{2.5}$ concentrations showed a significant increase from October to July. The safe limit established by the World Health Organization $\left(25 \mathrm{ug} / \mathrm{m}^{3}\right)$ was exceeded on eight days, reaching a maximum value of $41 \mu \mathrm{g} / \mathrm{m}^{3}$.

Table 2 shows the Pearson correlation matrix with the study variables. Table 3 presents the values of the coefficients provided through Poisson regression with the respective standard deviations

Table 1. Daily mean, maximum (Max) and minimum (Min) values and the respective standard deviations (SD) for $\mathrm{PM}_{2.5}$ concentrations $\left(\mu \mathrm{g} / \mathrm{m}^{3}\right)$, temperature $\left({ }^{\circ} \mathrm{C}\right)$, relative humidity (\%) and hospitalizations due to ischemic heart diseases. Taubaté, São Paulo, 2011-2012

\begin{tabular}{lcccc} 
Variables & Mean & SD & Min & Max \\
\hline $\mathrm{PM}_{2.5}$ & 13.2 & 5.6 & 0.4 & 41.2 \\
\hline Temperature & 22.9 & 3.9 & 9.8 & 38.4 \\
\hline Relative humidity & 95.3 & 8.7 & 45.0 & 100.0 \\
Hospitalizations & 0.9 & 0.9 & 0 & 4
\end{tabular}

$\mathrm{PM}_{2.5}=$ fine particulate matter.

Table 2. Correlation matrix for the variables of fine particulate matter $\left(\mathrm{PM}_{25}\right)$, temperature (Temp), relative humidity $(\mathrm{RH})$, hospitalizations (Hosp) and male and female sexes. Taubaté, São Paulo, 2011-2012

$\begin{array}{lcccccc} & \mathrm{PM}_{2.5} & \text { Temp } & \text { RH } & \text { Hosp } & \text { Male } & \text { Female } \\ \mathrm{PM}_{2.5} & 1.00 & 0.52^{*} & 0.13^{*} & 0.04 & 0.04 & 0.02 \\ \text { Temp } & & 1.00 & -0.07 & 0.15^{*} & 0.10 & 0.13^{*} \\ \mathrm{RH} & & & 1.00 & 0.02 & 0.08 & -0.08 \\ \text { Hosp } & & & & 1.00 & 0.86^{*} & 0.60^{*} \\ \text { Male } & & & & & 1.00 & 0.12^{*} \\ \text { Female } & & & & & & 1.00\end{array}$

${ }^{*}$ P-value $<0.05$.

Table 3. Coefficients provided by Poisson regression for hospital admissions in relation to fine particulate material concentrations, according to lags ( 0 to 7 days) and according to sex. Taubaté, São Paulo, 2011-2012

\begin{tabular}{lccc|} 
& Both sexes & Male & Female \\
\hline Lag 0 & $0.01158(0.01543)$ & $0.01109(0.01928)$ & $0.01207(0.02589)$ \\
\hline Lag 1 & $0.01774(0.01448)$ & $0.01676(0.01789)$ & $0.01795(0.02468)$ \\
\hline Lag 2 & $0.02118(0.01261)$ & $0.01034(0.01675)$ & $0.04300(0.01935)^{*}$ \\
Lag 3 & $0.01927(0.01443)$ & $0.01383(0.01776)$ & $0.02587(0.02487)$ \\
\hline Lag 4 & $0.03552(0.01266)^{*}$ & $0.03463(0.01534)^{*}$ & $0.03634(0.02247)$ \\
\hline Lag 5 & $0.03520(0.01274)^{*}$ & $0.04478(0.01470)^{*}$ & $0.01560(0.02559)$ \\
\hline Lag 6 & $0.00669(0.01440)$ & $0.00619(0.01670)$ & $0.01217(0.02823)$ \\
\hline Lag 7 & $-0.01189(0.01335)$ & $-0.00848(0.01566)$ & $-0.01943(0.02569)$ \\
\hline *-value $<0.05$. & &
\end{tabular}


for hospitalizations due to ischemic heart diseases, with delays of 0 to 7 days after $\mathrm{PM}_{2.5}$ exposure, among individuals of both sexes and stratified according to male and female sex. It was seen that admission was significantly associated with exposure to $\mathrm{PM}_{2.5}$ in the following situations: unstratified analyses at lag 4 ( $R R=1.04 ; 95 \%$ CI: $1.01-1.06)$ and at lag $5(\mathrm{RR}=1.04$; $95 \% \mathrm{CI}$ : 1.01-1.06); among males at lag $4(\mathrm{RR}=1.03 ; 95 \% \mathrm{CI}: 1.00-1.07)$ and at lag $5(\mathrm{RR}=1.05$; 95\% CI: 1.02-1.08); and among females at lag 2 ( $R R=1.04 ; 95 \%$ CI: 1.00-1.08). Thus, it was observed that the response among females was different and earlier.

In comparing the significant exposures between males and females (at lags 2, 4 and 5) and using equation (1), it was not possible to find any significant differences in the risks shown by the respective coefficients and standard errors. No overdispersion was identified.

Figure 1 shows the relative risk values and respective 95\% confidence intervals for both sexes and for the male and female sexes separately, according to an increase of $5 \mu \mathrm{g} / \mathrm{m}^{3}$ in $\mathrm{PM}_{2.5}$ concentrations. It was evident that the relative risk occurred earlier among females, i.e. at lag 2, without any corresponding occurrence in the analysis on males, or in the analysis on both sexes.

An increase of $5 \mu \mathrm{g} / \mathrm{m}^{3}$ in $\mathrm{PM}_{2.5}$ concentration increased the risk of hospitalization for both sexes by up to approximately $18 \%$. The PAR was estimated at approximately $15 \%$ and the PAF resulted in an excess of 59 hospitalizations, with expenditure of approximately US\$150,000.00, assuming an average cost of hospitalization of approximately US\$2,600.00.

\section{DISCUSSION}

This, to the best of our knowledge, was the first study estimating the effects of exposure to fine particulate matter in a mediumsized city, in relation to the number of hospitalizations due to ischemic heart diseases. The data used were estimated through mathematical modeling and the possible responses to exposure were estimated separately for males and females. An earlier female response was found, occurring two days after exposure (lag 2), but there was no significant difference in relation to the corresponding relative risk among males.

Tuan et al. ${ }^{14}$ examined pollutant concentration data that had been quantified by an environmental agency and found differences in the responses to these pollutants according to the subjects' sex, regarding the time of occurrence of the hospital admission. In the present study, the data used were estimated through mathematical modeling, whereas Tuan et al. ${ }^{14}$ used data quantified by the environmental agency of the state of São Paulo (CETESB).

Regarding the differences between the sexes, a study on deaths due to ischemic heart diseases that was conducted in all states of the United States between 2004 and 2007 showed that the mortality rate was higher among women than among men, especially among women aged less than 50 years. ${ }^{15,16}$ We found in our study that there were differences in lag, regarding exposure and hospitalization, and that the effect occurred earlier among females (lag 2) than among males (lags 4 and 5), i.e. four and five days after this exposure, in analyses on both sexes and on the male sex alone after stratification. Among females, this outcome occurred earlier in the study (only two days after exposure), and this result was concordant with the findings of Chen et al., ${ }^{17}$ who observed that the risk of dying from coronary disease was higher among women, especially among those in the postmenopausal period, than among men. ${ }^{17}$ One possible explanation for the difference in the effects of exposure to $\mathrm{PM}_{10}$ and $\mathrm{PM}_{2.5}$ between men and women may be that the deposition of these particles is more localized and more intense in females. The smaller number of red blood cells in women may make them more sensitive to the toxic effects of air pollutants. ${ }^{21}$

In studies conducted in Brazil, the effects of exposure to air pollutants have been shown to be associated with hospitalizations due to cardiovascular diseases such as hypertension, acute myocardial infarction and stroke..$^{6,18-20}$ Specifically in relation to the association between exposure to particulate matter and hospitalizations due to ischemic heart disease, a study carried out in São José dos Campos, a city near Taubaté, showed that an increase in $\mathrm{PM}_{10}$ concentration of $16 \mu \mathrm{g} / \mathrm{m}^{3}$ led to a $10 \%$ increase in the relative risk of hospitalization. However, in that study, the subjects were not stratified according to sex. ${ }^{18}$

In the case of cardiovascular diseases, the data estimated through this model in another study made it possible to identify an excess of hospitalizations, of the order of 650, in São José do Rio Preto, that occurred through an increase in $\mathrm{PM}_{2.5}$ concentrations, with excess expenditure of US\$ 1 million. That study was the only previous study carried out in the state of São Paulo, to the best of our knowledge. ${ }^{20}$

The direct effects of this exposure may occur through agents that cross the pulmonary epithelium in the circulation, such as gases and possibly ultrafine particles $(<0.1 \mu)$, along with soluble constituents

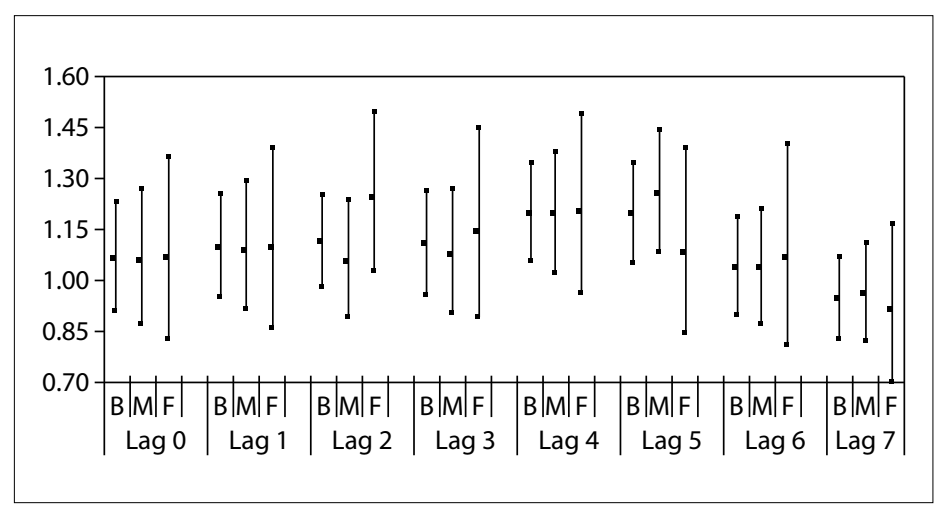

Figure 1. Relative risk with respective $95 \%$ confidence intervals, according to a $5 \mu \mathrm{g} / \mathrm{m}^{3}$ increase in fine particulate matter concentration, for both sexes (B) and for males (M) and females (F). Taubaté (SP), 2011-2012. 
of $\mathrm{PM}_{2.5}$ (e.g. transition metals). In addition, activation of pulmonary neural reflexes secondary to interactions between particulate matter and pulmonary receptors may play an important role. These direct effects of air pollution provide a plausible explanation for occurrences of rapid cardiovascular responses (within a few hours), such as myocardial infarction. The less acute (several hours to days) and chronic indirect effects of air pollution may occur through pulmonary oxidative stress/inflammation induced by inhaled pollutants. Subsequently, this may contribute towards a systemic inflammatory state, which may, in turn, be able to activate hemostatic pathways, impair vascular function and accelerate atherosclerosis. ${ }^{25}$

The present study had some limitations, and the way in which pollutant concentrations were estimated was one of them. This was done through mathematical modeling and may have provided incorrect data. Another limitation was that the hospitalization data were secondary, even though they came from an official source. These data had the potential to incorporate diagnostic errors or incorrect addresses for the subjects. Additionally, this data source does not contain information on habits such as smoking or sedentary lifestyle, or on comorbidities or family history. It is also important to note that the results presented here do not represent causality, but show an association between the exposure and the outcome. Nonetheless, use of data estimated through the CCATT-BRAMS model, which has already been implemented in other studies, may form an alternative for studies on the effects of exposure to fine particulate matter on human health, such as in relation to respiratory and cardiovascular diseases. ${ }^{22-25}$

\section{CONCLUSIONS}

Notwithstanding the possible limitations, the findings from this study, using data estimated through a mathematical model, suggest that an association exists between exposure to $\mathrm{PM}_{2.5}$ and hospitalizations due to cardiovascular diseases and that this exposure may differ according to sex.

\section{REFERENCES}

1. Brasil. Ministério da Saúde. Departamento de Informática do SUS (DATASUS). Available from: http://tabnet.datasus.gov.br/cgi/deftohtm. exe?sih/cnv/nrsp.def. Accessed in 2018 (Jun 18).

2. CETESB - Companhia Ambiental do Estado de São Paulo. Publicações, relatórios, guias e manuais. Available from: http://cetesb.sp.gov.br/ publicacoes-relatorios/. Accessed in 2018 (Jun 21).

3. Souza PA, Mello WZ, Mariani RL, Sella SM. Variações temporais do material particulado inalável fino e grosso e íons inorgânicos solúveis em São José dos Campos, SP. Rev Bras Geof. 2011;29(1):71-82. doi: 10.1590/S0102-261X2011000100005.

4. Kim KH, Kabir E, Kabir S. A review on the human health impact of airborne particulate matter. Environ Int. 2015;74:136-46. PMID: 25454230; doi: 10.1016/j.envint.2014.10.005.
5. Dockery DW. Epidemiologic evidence of cardiovascular effects of particulate air pollution. Environ Health Perspect. 2001;109 Suppl 4:483-6. PMID: 11544151; doi: 10.2307/3454657.

6. Nascimento LFC, Francisco JB, Patto MBR, Antunes AM. Environmental pollutants and stroke-related hospital admissions. Cad. Saúde Pública. 2012;28(7):1319-24. PMID: 22729262; doi: 10.1590/S0102$311 \times 2012000700010$

7. Cakmak S, Dales RE, Judek S. Do gender, education, and income modify the effect of air pollution gases on cardiac disease? J Occup Environ Med. 2006;48(1):89-94. PMID: 16404215; doi: 10.1097/01. jom.0000184878.11956.4b.

8. Miller KA, Siscovick DS, Sheppard L, et al. Long-term exposure to air pollution and incidence of cardiovascular events in women. N Engl J Med. 2007;356(5):447-58. PMID: 17267905; doi: 10.1056/NEJMoa054409.

9. Clougherty JE. A growing role for gender analysis in air pollution epidemiology. Environ Health Perspect. 2010;118(2):167-76. PMID: 20123621; doi: 10.1289/ehp.0900994.

10. Freitas SR, Longo KM, Silva Dias MAF, et al. The Coupled Aerosol and Tracer Transport model to the Brazilian developments on the Regional Atmospheric Modeling System (CATT-BRAMS). Part 1: Model description and evaluation. Atmos Chem Phys Discuss 2009; 9(8):2843-61. doi: 10.5194/acp-9-2843-2009.

11. Ignotti $E$, Valente JG, Longo KM, et al. Impact on human health of particulate matter emitted from burning in the Brazilian Amazon region. Rev Saúde Pública. 2010;44(1):121-30. PMID: 20140336; doi: 10.1590/S0034-89102010000100013

12. César AC, Carvalho JA Jr, Nascimento LF. Association between NOx exposure and deaths caused by respiratory diseases in a medium-sized Brazilian city. Braz J Med Biol Res. 2015;48(12):1130-5. PMID: 26421866; doi: 10.1590/1414-431X20154396.

13. Zeka A, Zanobetti A, Schwartz J. Individual-level modifiers of the effects of particulate matter on daily mortality. Am J Epidemiol. 2006;163(9):849-59. PMID: 16554348; doi: 10.1093/aje/kwj116.

14. Tuan TS, Venâncio TS, Nascimento LF. Effects of Air Pollutant Exposure on Acute Myocardial Infarction, According to Gender. Arq Bras Cardiol. 2016;107(3):216-22. PMID: 27533257; doi: 10.5935/abc.20160117.

15. Kan H, London SJ, Chen G, et al. Season, sex, age, and education as modifiers of the effects of outdoor air pollution on daily mortality in Shanghai, China: The public health and air pollution in Asia (PAPA) study. Environ Health Perspect. 2008;116(9):1183-8. PMID: 18795161; doi: 10.1289/ehp.10851.

16. Zhang Z, Fang J, Gillespie C, et al. Age-specific gender differences in in-hospital mortality by type of acute myocardial infarction. Am J Cardiol. 2012;109(8):1097-103. PMID: 22245410; doi: 10.1016/j. amjcard.2011.12.001.

17. Chen LH, Knutsen SF, Shavlik D, et al. The association between fatal coronary heart disease and ambient particulate air pollution: are females at greater risk? Environ Health Perspect. 2005;113(12):1723-9. PMID: 16330354; doi: 10.1289/ehp.8190. 
18. Nascimento LF. Air pollution and cardiovascular hospital admissions in a medium-sized city in São Paulo State, Brazil. Braz J Med Biol Res. 2011;44(7):720-4. PMID: 21710102; doi: 10.1590/S0100$879 \times 2011007500079$.

19. Nascimento LFC, Francisco JB. Particulate matter and hospital admission due to arterial hypertension in a medium-sized Brazilian city. Cad Saúde Pública 2013;29(8):1565-71. PMID: 24005922; doi: 10.1590/0102$311 \times 00127612$

20. Mantovani KC, Nascimento LF, Moreira DS, Vieira LC, Vargas NP. Air pollutants and hospital admissions due to cardiovascular diseases in São José do Rio Preto, Brazil. Ciênc Saúde Colet. 2016;21(2):509-15. PMID: 26910158; doi: 10.1590/1413-81232015212.16102014.

21. Brook RD, Franklin B, Cascio W, et al. Air pollution and cardiovascular disease: a statement for healthcare professionals from the Expert Panel on Population and Prevention Science of the American Heart Association. Circulation. 2004;109(21):2655-71. PMID: 15173049; doi: 10.1161/01.CIR.0000128587.30041.C8.

22. Roman VVL, Carvalho Jr JA, Nascimento LFC, Cesar ACG. Efeitos de poluentes do ar e doenças respiratórias utilizando dados estimados por modelo matemático [Effects of air pollutants on respiratory diseases using estimated values by mathematical modelling of simulation]. Rev Ambient Água. 2015;10(4):825-31. doi: 10.4136/ ambi-agua.1592.

23. César AC, Nascimento LF, Mantovani KC, Vieira LCP. Fine particulate matter estimated by mathematical model and hospitalizations for pneumonia and asthma in children. Rev Paul Pediatr. 2016;34(1):18-23. PMID: 26522821; doi: 10.1016/j.rppede.2015.12.005.

24. Nascimento LF, Vieira LC, Mantovani KC, Moreira DS. Air pollution and respiratory diseases: ecological time series. São Paulo Med J. 2016;134(4):315-21. PMID: 27581332; doi: 10.1590/15163180.2015.0237250216.

25. Machin AB, Nascimento LFC. Efeitos da exposição a poluentes do ar na saúde das crianças de Cuiabá, Mato Grosso, Brasil [Effects of exposure to air pollutants on children's health in Cuiabá, Mato Grosso State, Brazil]. Cad Saúde Pública. 2018;34(3):e00006617. PMID: 29538512; doi: 10.1590/0102-311×00006617.

Acknowledgements: Paola C. Ribeiro thanks the UNITAU Pro-Rectory for Research and Postgraduate Studies for its financial support (procedural no. 29/2016). Luiz Fernando C. Nascimento thanks Conselho Nacional de Desenvolvimento Científico e Tecnológico (CNPq) for its research productivity scholarship (\# 308297/2011-3)

Sources of funding: There are no funders to report for this submission Conflict of interest: None
Date of first submission: June 27, 2018

Last received: December 26, 2018

Accepted: January 4, 2019

\section{Address for correspondence:}

Luiz Fernando Costa Nascimento

Programa de Pós-Graduação em Ciências Ambientais, Universidade de Taubaté (UNITAU)

Av. Ariberto Pereira da Cunha, 333

Guaratinguetá (SP) - Brasil

CEP $12516-410$

Tel. (+55 12) 3123-2161

E-mail: luiz.nascimento@pq.cnpq.br 